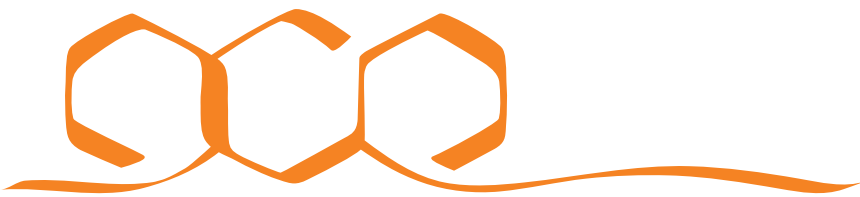 COMMUNICATIONS CHEMISTRY
}

\section{Author Correction: Understanding zeolite deactivation by sulfur poisoning during direct olefin upgrading}

Jonathan H. Harrhy' ${ }^{1}$, Aiguo Wang ${ }^{1}$, Jack S. Jarvis ${ }^{1}$, Peng He ${ }^{1}{ }^{1}$, Shijun Meng ${ }^{1}$, Matthew Yung ${ }^{2}$, Lijia Liu ${ }^{3} \&$ Hua Song (iD ${ }^{1}$

Correction to: Communications Chemistry https://doi.org/10.1038/s42004-019-0141-4, published online 25 March 2019

The original PDF and HTML versions of this Article contained an error in the Acknowledgements section. In the Acknowledgements section MEG Energy Corp. was incorrectly acknowledged for financial support. The correct Acknowledgements text is as follows:

The authors gratefully acknowledge the financial support from Alberta Innovates-Energy and Environment Solutions. We appreciate the XAS facilities provided by Taiwan Photon Source. The technical support from Dr. Lo Yueh Chang and TPS 44A beamline is acknowledged.

This has been corrected in both the PDF and HTML versions of the Article.

Published online: 09 April 2019

(c) Open Access This article is licensed under a Creative Commons Attribution 4.0 International License, which permits use, sharing, adaptation, distribution and and indicate if changes were made. The images or other third party material in this article are included in the article's Creative Commons license, unless indicated otherwise in a credit line to the material. If material is not included in the article's Creative Commons license and your intended use is not permitted by statutory regulation or exceeds the permitted use, you will need to obtain permission directly from the copyright holder. To view a copy of this license, visit http://creativecommons.org/licenses/by/4.0/.

(C) The Author(s) 2019

\footnotetext{
${ }^{1}$ Department of Chemical and Petroleum Engineering, University of Calgary, Calgary T2N 1N4 AB, Canada. ${ }^{2}$ National Bioenergy Center, National Renewable Energy Laboratory, 15013 Denver West Parkway, Golden, CO 80401, USA. ${ }^{3}$ Jiangsu Key Laboratory for Carbon-Based Functional Materials \& Devices, Institute of Functional Nano and Soft Materials (FUNSOM), Soochow University-Western University Centre for Synchrotron Radiation Research, Soochow University, Suzhou, Jiangsu 215123, China. Correspondence and requests for materials should be addressed to H.S. (email: sonh@ucalgary.ca)
} 